\title{
Attitude and Practice of Birth Attendants Regarding the Presence of Male Partner at Delivery in Nigeria
}

\author{
Abiodun Adeniran ${ }^{*}$, Kikelomo Adesina ${ }^{1}$, Abiodun Aboyeji ${ }^{1}$, Olayinka \\ Balogun $^{1}$, Peace Adeniran², Adegboyega Fawole ${ }^{1}$
}

ABSTRACT

\section{OPEN ACCESS}

Citation: Abiodun Adeniran, Kikelomo Adesina, Abiodun Aboyeji, Olayinka Balogun, Peace Adeniran, Adegboyega Fawole. Attitude and Practice of Birth Attendants Regarding the Presence of Male Partner at Delivery in Nigeria. Ethiop J Health Sci 2017;27(1):107. doi: http://dx.doi.org/10.4314/ejhs.v27i2.2

Received: December 1, 2016

Accepted: December 3, 2016

Published: March 1, 2017

Copyright: @ 2015 Adeniran A, et al.

This is an open access article distributed

under the terms of the Creative Commons

Attribution License, which permits

unrestricted use, distribution, and reproduction in any medium, provided the original author and source are credited

Funding: Nill

Competing Interests: The authors

declare that this manuscript was approved by all authors in its form and that no

competing interest exists.

Affiliation and Correspondence:

${ }^{1}$ Department of Obstetrics and

Gynecology, University of Ilorin/

University of Ilorin Teaching Hospital,

Ilorin, Nigeria

${ }^{2}$ Nursing Services Department,

University of Ilorin Teaching Hospital,

Ilorin

*Email: acrowncord@hotmail.com
BACKGROUND: Despite increasing request for the male partners' presence at delivery in developing countries, the view and practice of birth attendants remained poorly understood.This study aimed to evaluate the perception, attitude and practice of birth attendants concerning the requests in Nigeria.

METHODS: A prospective, cross-sectional survey involving consenting birth attendants was conducted in six public and six private health facilities in North Central Nigeria. Statistical analysis was done with SPSS-version 20.0; p-value $<0.05$ was considered statistically significant.

RESULTS: Among 564 participants (24.8\% male, $75.2 \%$ female), 465(82.4\%) support the presence of male partners at delivery, 409(72.5\%) desire to be with their partner at delivery, 434(77.0\%) had previous request for male partner's presence at delivery while $225(51.8 \%)$ declined it due to perception that men will disturb. Among the male partners allowed at delivery, 92(44.0\%) did not disturb the birth attendant while $5(2.4 \%)$ ended in litigation. Among birth attendants who allowed men at delivery in the past, $160(76.6 \%)$ will allow men in the future. There was no statistical significance regarding the age, gender, cadre or year of service of birth attendants and attitude to a protocol change to allow men at delivery. Birth attendants who support the presence of men at delivery showed positive attitude (OR33.178, 95\% CI6.996-157.358; $p<0.001)$ while those who opined that men would disturb at delivery had a negative attitude (OR0.306, 95\%CI0.124-0.755); p0.010) to possible protocol change.

CONCLUSION: Despite perceived negative effects of allowing male partners at delivery, many birth attendants are willing to allow them if necessary structural modifications are instituted.

KEYWORDS: Male partner, Men at delivery, Birth Attendant, Labour companionship 


\section{INTRODUCTION}

Continuous Intrapartum support has been advocated to be made the norm because it is beneficial in reducing labour analgesia use, operative birth or dissatisfaction about birthing experience (1). This has encouraged theparticipatory role of male partners during delivery in developed countries. Couples in developing countries are increasingly expressing their desire for the partner's presence in labour and delivery with $84.4 \%$ of parturient desiring company during delivery while $80.8 \%$ preferred the male partner (2) in Ilorin, Nigeria.

Some birth attendants oppose the presence of the male partners at delivery arguing that the men may find the experience emotionally traumatic, or interfere with the work of the staff $(3,4)$. Emergency room nurses have reported that they felt uncomfortable with having family members look over their shoulders to monitor their every move during resuscitation $(3,5)$. The male partner's presence has been viewed as possible compensation for inadequate staffing as they are more likely to touch their partners during labour than other support figures (6). Another report showed that support during delivery provided by a close individual especially the baby's father creates a more positive childbirth experience for the mother with less pain (7).

Although a major obstacle to the presence of male partner at delivery is the state of most health facilities in developing countries, the attitude of birth attendants has not been adequately explored. This study is thus aimed at determination of the perception, attitude and practice of birth attendants regarding the presence of male partners at delivery in Nigeria.

\section{MATERIALS AND METHODS}

The study was a prospective, cross-sectional survey conducted in North Central Nigeria. It involved six public and six private health facilities making a total of twelve facilities.

Study population: Participants were birth attendants who conduct deliveries in the study area (Community Health Extension workers [CHEW], Nurses, Nurse/Midwives and Doctors) currently employed in both public and private facilities during the study period.

Inclusion criteria: Birth attendants in the selected birth attendant groups working at the selected study sites who were informed about the study and consented to participate were recruited into the study.

Exclusion criteria: Birth attendants who were unwilling to participate and those employed at facilities that were not selected for the study were excluded from the study.

Study protocol: All eligible participants were informed about the study, and informed consent was obtained. Thereafter, each participant completed a self-administered questionnaire: the information collected included demographic parameters, place of employment, duration of service, cadre as well as perception, attitude and practice regarding the presence of male partner at labour and delivery. Participants' confidentiality was maintained by using codes instead of names and keeping the data away from non-members of the research team.

Sample size calculation/ sampling technique: The sample size was calculated using the formula for cross-sectional survey (8) using prevalence of $14.2 \%$ male partner attendance at delivery in the study area (2), 95\% confidence interval, degree of accuracy of 0.05 and attrition rate of $20 \%$ to give a minimum sample size of 221. In addition, the design effect was 2.5. Therefore, the minimum sample size for the study was 508 (i.e. $221 \times 2.5$ ).

The sampling technique used for the study was stratified ransom sampling. This involved selection of twelve participating health facilities (six public and six private facilities) from the list of registered facilities at the Ministry of Health. The facilities were divided into public and private; the names of all facilities in each group were written on pieces of paper and six were picked from each pool while individual participants were randomly selected at each facility.

Ethical approval: Ethical approval was obtained from the Ethical Review Committee of the University of Ilorin Teaching Hospital (UITH), Ilorin, before the commencement of the study.

Statistical analysis: Statistical analysis was done with SPSS version 20.0. The results were expressed in tables with percentages. Pearson's

DOI: http://dx.doi.org/10.4314/ejhs.v27i2.2 
chi square was used for comparison with calculation of odds ratio at $95 \%$ confidence interval; logistic regression and $\mathrm{p}$ value $<0.05$ was termed significant.

\section{RESULTS}

Among the 564 participants, 424(75.2\%) were females, 196(34.8\%) were double qualified nurse/midwife and $157(27.8 \%)$ were medical doctors. Also, 157(27.8\%) were employed at private health facilities. Year of service was $\leq 10$ in $362(64.2 \%)$ while $324(57.4 \%)$ conducted last delivery in less than six months prior to the study (Table 1).

Table 1: Biosocial characteristics of participating birth attendants

\begin{tabular}{lcc}
\hline Variables & Frequency $(\mathbf{N}=\mathbf{5 6 4})$ & Percent \\
\hline $\begin{array}{l}\text { Age group } \\
\leq 25\end{array}$ & 74 & \\
$26-35$ & 282 & 13.1 \\
$36-45$ & 123 & 50.0 \\
$46-55$ & 68 & 21.8 \\
$>55$ & 17 & 12.1 \\
Gender & & 3.0 \\
Male & 140 & 24.8 \\
Female & 424 & 75.2 \\
Cadre & & \\
CHEW & 95 & 16.8 \\
Nurse & 116 & 20.6 \\
Nurse/ Midwife & 196 & 34.8 \\
Medical doctor & 157 & 27.8 \\
Place of employment & & \\
Primary & 58 & 10.3 \\
Secondary & 111 & 19.7 \\
Tertiary & 238 & 42.2 \\
Private & 157 & 27.8 \\
Years of experience & & \\
$0-10$ & 362 & 64.2 \\
$11-20$ & 113 & 20.0 \\
$>$ 20 & 89 & 15.8 \\
Last time conducted delivery (months) & & 30.9 \\
Never & & \\
<6 & 19 & 57.4 \\
- 12 & 324 & \\
$>12$ & 47 & \\
\hline & 174 & \\
\hline
\end{tabular}

In Table 2, 465(82.4\%) supported the presence of male partner at labour/delivery, 434(77.0\%) had had request for male partner's presence at delivery in the past, 209(37.1\%) granted the request,
$92(44.0 \%)$ of the men did not disturb the health provider while $5(2.4 \%)$ resulted in litigation, but $160(76.6 \%)$ of health providers will allow the male partner at delivery in the future. 
Table 2: Views and practice of birth attendants to presence of male partner at delivery.

\begin{tabular}{|c|c|c|}
\hline Variable & Frequency & Percent \\
\hline \multicolumn{3}{|c|}{ Should male partners be allowed in labour/ delivery? } \\
\hline Yes & 465 & 82.4 \\
\hline No & 99 & 17.6 \\
\hline \multicolumn{3}{|c|}{$\begin{array}{l}\text { Will you like your partner to be with you orstay with your } \\
\text { partner during labour and delivery? }\end{array}$} \\
\hline Yes & 409 & 72.5 \\
\hline No & 155 & 27.5 \\
\hline \multicolumn{3}{|c|}{ Have you had request for male partner at delivery before? } \\
\hline Yes & 434 & 77.0 \\
\hline No & 130 & 23.0 \\
\hline \multicolumn{3}{|l|}{ What was your response? $n=434$} \\
\hline I allowed the man to be with his wife & 209 & 37.1 \\
\hline I disallowed the request & 225 & 39.9 \\
\hline \multicolumn{3}{|c|}{ Describe the experience of male partners' presence?n=209 } \\
\hline He did not disturb & 92 & 44.0 \\
\hline He disturbed me from doing my work & 23 & 11.0 \\
\hline He took hospital to court after the delivery & 5 & 2.4 \\
\hline He was afraid & 63 & 30.2 \\
\hline He fainted & 5 & 2.4 \\
\hline He was crying & 21 & 10.0 \\
\hline \multicolumn{3}{|c|}{$\begin{array}{l}\text { How will you respond to request for male partner at delivery } \\
\text { in the future? } n=209\end{array}$} \\
\hline Yes & 160 & 76.6 \\
\hline No & 49 & 23.4 \\
\hline \multicolumn{3}{|c|}{ Reason for refusing male partner's presence. $n=225$} \\
\hline He may not like the female partner afterwards & 4 & 1.8 \\
\hline He may collapse at sight of blood & 8 & 3.6 \\
\hline The woman may not push well at delivery & 12 & 5.3 \\
\hline He has no role to play & 12 & 5.3 \\
\hline He may sue the hospital afterwards & 53 & 23.6 \\
\hline He may disturb birth attendant & 136 & 60.4 \\
\hline \multicolumn{3}{|c|}{ Do you favor protocol change to allow men at delivery? } \\
\hline Yes & 401 & 71.1 \\
\hline No & 163 & 28.9 \\
\hline \multicolumn{3}{|c|}{$\begin{array}{l}\text { Will it be necessary to restructure hospital for men to be at } \\
\text { labour/delivery? }\end{array}$} \\
\hline Yes & 341 & 60.4 \\
\hline No & 223 & 39.6 \\
\hline
\end{tabular}

From Table 3, the attitude of the birth attendant to the presence of male partner at delivery was not statistically significant relative to the age groups (p0.761), gender (p0.257), cadre (p0.590), place of employment (p0.214), years of service (p0.687) and last time the birth attendant conducted the last delivery (p0.568).

The response of birth attendants to a policy change to allow men at delivery was not statistically significant among the age groups (p0.904), gender (0.526), cadre of birth attendant

DOI: http://dx.doi.org/10.4314/ejhs.v27i2.2 
(p0.157), place of employment (p0.523), years of service (p0.513) and time of last delivery conducted by the birth attendant (p0.612) (Table $4)$.

Table 5 shows that the significant predictors of positive attitude to allow the male partner at delivery were opinion in support of allowing men at delivery (OR33.178, 95\%CI6.996-157.36; $\mathrm{p}<0.001)$ and opinion that men will disturb at delivery (OR0.306, 95\%CI 0.124-0.755; p0.010) while the opinion that delivery is sacred for women was not significant (OR0.139, 95\%CI 0.019-1.001; p0.050).

Table 3: Attitudes to presence of male partner at delivery among birth attendants

\begin{tabular}{|c|c|c|c|c|c|}
\hline \multirow[b]{2}{*}{ Variables } & \multicolumn{3}{|c|}{$\begin{array}{c}\text { Attitude to presence of male partner at } \\
\text { delivery }\end{array}$} & \multirow[b]{2}{*}{$\chi^{2}$} & \multirow[b]{2}{*}{$p$ value } \\
\hline & $\begin{array}{l}\text { Positive } \\
\text { n }(\%)\end{array}$ & $\begin{array}{l}\text { Negative } \\
\text { n }(\%)\end{array}$ & $\begin{array}{l}\text { Total } \\
\text { n }(\%)\end{array}$ & & \\
\hline \multicolumn{6}{|l|}{ Age group } \\
\hline$\leq 25$ & $59(12.7)$ & $15(15.2)$ & $74(13.1)$ & 1.865 & 0.761 \\
\hline $26-35$ & $238(51.2)$ & $44(44.4)$ & $282(50.0)$ & & \\
\hline $36-45$ & $99(21.3)$ & $24(24.2)$ & $123(21.8)$ & & \\
\hline $46-55$ & $56(12.0)$ & $12(12.1)$ & $68(12.1)$ & & \\
\hline$>55$ & $13(2.8)$ & $4(4.0)$ & $17(3.0)$ & & \\
\hline \multicolumn{6}{|l|}{ Gender } \\
\hline Male & $111(23.9)$ & $29(29.3)$ & $140(24.8)$ & 1.286 & 0.257 \\
\hline Female & $354(76.1)$ & $70(70.7)$ & $424(75.2)$ & & \\
\hline \multicolumn{6}{|l|}{ Cadre } \\
\hline CHEW & $75(16.1)$ & $18(18.2)$ & $93(16.5)$ & 2.811 & 0.590 \\
\hline Nurse & $101(21.7)$ & $15(15.2)$ & $116(20.6)$ & & \\
\hline Nurse/ Midwife & $158(34.0)$ & $38(38.4)$ & $196(34.8)$ & & \\
\hline Medical doctor & $129(27.7)$ & $28(28.3)$ & $157(27.8)$ & & \\
\hline \multicolumn{6}{|c|}{ Place of employment } \\
\hline Primary & $53(11.4)$ & $5(5.1)$ & $58(10.3)$ & 4.477 & 0.214 \\
\hline Secondary & $87(18.7)$ & $24(24.2)$ & $111(19.7)$ & & \\
\hline Tertiary & $196(42.2)$ & $42(42.4)$ & $238(42.2)$ & & \\
\hline Private & $129(27.7)$ & $28(28.3)$ & $157(27.8)$ & & \\
\hline \multicolumn{6}{|c|}{ Years of experience } \\
\hline $0-10$ & $295(63.4)$ & $67(67.6)$ & $362(64.2)$ & 0.750 & 0.687 \\
\hline $11-20$ & $96(20.6)$ & $17(17.2)$ & $113(20.0)$ & & \\
\hline$>20$ & $74(15.9)$ & $15(15.2)$ & $89(15.8)$ & & \\
\hline \multicolumn{6}{|c|}{$\begin{array}{l}\text { Last time conducted delivery } \\
\text { (months) }\end{array}$} \\
\hline Never & $17(3.7)$ & $2(2.0)$ & $19(3.4)$ & 2.020 & 0.568 \\
\hline$<6$ & $270(58.1)$ & $54(54.5)$ & $324(57.4)$ & & \\
\hline $6-12$ & $36(7.7)$ & $11(11.1)$ & $47(8.3)$ & & \\
\hline$>12$ & $142(30.5)$ & $32(32.3)$ & $174(30.9)$ & & \\
\hline
\end{tabular}

DOI: http://dx.doi.org/10.4314/ejhs.v27i2.2 
Table 4: Birth attendant response to possible policy change to allow men at delivery

\begin{tabular}{|c|c|c|c|c|c|}
\hline \multirow[b]{2}{*}{ Variables } & \multicolumn{3}{|c|}{$\begin{array}{c}\text { Response to policy change to allow men at } \\
\text { delivery }\end{array}$} & \multirow[b]{2}{*}{$\chi^{2}$} & \multirow[b]{2}{*}{$p$ value } \\
\hline & $\begin{array}{c}\text { Positive } \\
\text { n }(\%)\end{array}$ & $\begin{array}{l}\text { Negative } \\
\text { n }(\%)\end{array}$ & $\begin{array}{l}\text { Total } \\
\text { n }(\%)\end{array}$ & & \\
\hline \multicolumn{6}{|l|}{ Age group } \\
\hline$\leq 25$ & $47(13.1)$ & $27(13.1)$ & $74(13.1)$ & 1.037 & 0.904 \\
\hline $26-35$ & $182(50.8)$ & $100(48.5)$ & $282(50.0)$ & & \\
\hline $36-45$ & $78(21.8)$ & $45(21.8)$ & $123(21.8)$ & & \\
\hline $46-55$ & $42(11.7)$ & $26(12.6)$ & $68(12.1)$ & & \\
\hline$>55$ & $9(2.5)$ & $8(3.9)$ & $17(3.0)$ & & \\
\hline \multicolumn{6}{|l|}{ Gender } \\
\hline Male & $92(25.7)$ & $48(23.3)$ & $140(24.8)$ & 0.403 & 0.526 \\
\hline Female & $266(74.3)$ & $158(76.7)$ & $424(75.2)$ & & \\
\hline \multicolumn{6}{|l|}{ Cadre } \\
\hline CHEW & $54(15.1)$ & $39(18.9)$ & $93(16.5)$ & 6.621 & 0.157 \\
\hline Nurse & $73(20.4)$ & $43(20.9)$ & $116(20.6)$ & & \\
\hline Nurse/ Midwife & $123(34.4)$ & $73(35.4)$ & $196(34.8)$ & & \\
\hline Medical doctor & $108(30.2)$ & $49(23.8)$ & $157(27.8)$ & & \\
\hline \multicolumn{6}{|c|}{ Place of employment } \\
\hline Primary & $38(10.6)$ & $20(9.7)$ & $58(10.3)$ & 2.246 & 0.523 \\
\hline Secondary & $73(20.4)$ & $38(18.4)$ & $111(19.7)$ & & \\
\hline Tertiary & $155(43.3)$ & $83(40.3)$ & $238(42.2)$ & & \\
\hline Private & $92(25.7)$ & $65(31.6)$ & $157(27.8)$ & & \\
\hline \multicolumn{6}{|c|}{ Years of experience } \\
\hline $0-10$ & $236(65.9)$ & $126(61.2)$ & $362(64.2)$ & 1.336 & 0.513 \\
\hline $11-20$ & $69(19.3)$ & $44(21.4)$ & $113(20.0)$ & & \\
\hline$>20$ & $53(14.8)$ & $36(17.5)$ & $89(15.8)$ & & \\
\hline \multicolumn{6}{|c|}{ Last time conducted delivery } \\
\hline Never & $12(3.4)$ & $7(3.4)$ & $19(3.4)$ & 1.812 & 0.612 \\
\hline$<6$ & $213(59.5)$ & $111(53.9)$ & $324(57.4)$ & & \\
\hline $6-12$ & $29(8.1)$ & $18(8.7)$ & $47(8.3)$ & & \\
\hline$>12$ & $104(29.1)$ & $70(34.0)$ & $174(30.9)$ & & \\
\hline
\end{tabular}

Table 5: Predictors of positive attitude to policy change to allow men in delivery room

\begin{tabular}{lccccc}
\hline Variables & B & $p$ value & OR & \multicolumn{2}{c}{ 95\% C.I } \\
& & & & Lower & Upper \\
\hline Men should be allowed in delivery room & 3.502 & $<0.001^{*}$ & 33.178 & 6.996 & 157.358 \\
Delivery is sacred for women & -1.1973 & 0.050 & 0.139 & 0.019 & 1.001 \\
Men will disturb during delivery & -1.185 & $0.010^{*}$ & 0.306 & 0.124 & 0.755 \\
\hline
\end{tabular}

Abbreviation: $\mathrm{B}=$ Coefficient of Binary logistic regression; OR = Odds ratio; C.I = Confidence Interval; ${ }^{*}=\mathrm{p}<0.05$ $\mathrm{R}^{2}: 0.345$. Predictive value: $83.3 \% . \chi^{2}: 47.481 p:<0.001$

Variables excluded by the model: age, gender, cadre, duration of qualification, place of employment, last conducted delivery, would like to be with wife or husband at delivery, previous experience with a man at delivery, men may cry during the delivery, do not have any role to play, may collapse and faint on seeing blood, may not like their wives after delivery and may feel ashamed; the woman may not push well

DOI: http://dx.doi.org/10.4314/ejhs.v27i2.2 


\section{DISCUSSION}

In this study, about four-fifth of birth attendants supported the presence of male partners at delivery, three quarters had had such requests in the past, but about half of these granted the request. Refusal of the male partners' presence by birth attendants was commonly due to the perception that men will disturb the health provider and fear of litigation. Birth attendants who had allowed the male partners to be present at delivery in the past described the partners' presence as satisfactory and that will be granted for the future. The attitude of the birth attendant to the presence of male partner at delivery was not statistically significant relative to the attendant's age, gender, cadre, place of employment, years of service or frequency of conducting delivery.

Although not yet viewed as routine, there are reports of increase in the request by women and their partners for the male partners' presence at delivery in developing countries (2,9-11). However, the responses of birth attendants are divided relative to the request; those with a positive attitude are enthusiastic to see it implemented (10). Conversely, there are those who oppose the idea because of the perception that the men are likely to interfere with staff work and decision making or institute malpractice claims (12). Such workers show a negative attitude towards men's participation (9) with reports of denial of the request (13). A report from Nigeria showed that the leading cause of male partner absence at delivery was refusal by the birth attendant, and the majority of parturient whose partner were at their delivery described the experience as satisfactory (2). The concern that men, if allowed at labour and delivery, may disturb the staff is not limited to birth attendants; $27.9 \%$ of parturients expressed the same opinion as reported in a previous study (2).

The attitude of birth attendants may be influenced by cultur, occupation and previous experiences of allowing the partner into the delivery room (4). From this study, most birth attendants who allowed men at delivery in the past were willing to grant such request in the future. However, the policy at most facilities did not support the request while others were limited in manpower and space necessitating a restriction in the access granted to the male partner (10). Many health facilities in developing countries have couple unfriendly delivery units with crowded wards and more than one delivery beds in one suite making companionship impossible $(9,13)$. At other instances, the men did not make a request to be present because they had heard that other men were previously denied entry (9).

Apart from individual preferences, responses of birth attendants may depend on their professional group. Midwives have been reported as more strongly supportive than doctors in allowing the male partner because they have been with the clients throughout the antenatal period (5). However, anesthesiologists were not supportive because their work may involve critical care, and their encounter with the couple at delivery is usually the first (5).

Globally, obstetric services contribute a sizable share of medical litigations; there are genuine concerns that allowing the male partner may increase obstetric litigations (12). In addition, some nursing staff report being uncomfortable and uneasy with the presence of family members who may be watching their activities at neonatal resuscitation and possibly misinterpret the actions resulting in avoidable litigations (14). The experiences of birth attendants who allowed men at delivery in this study showed that $2.4 \%$ resulted in litigations. This emphasizes that this is a litigation-prone setting thereby requiring professionalism and caution.

Most birth attendants in developing countries do not view the male partners as clients nor do they understand that the men undergo emotional and practical preparations for parenting as their wives do. Such that while the women are educated and prepared for parenting, the men are generally unattended to. Furthermore, employers of awaiting-fathers do not oblige them to fulfill their roles with no provision to accompany the women to antenatal clinics or delivery (13). Most antenatal clinics in developing countries have no provision for the male partner during their activities or consultations (9). Thus, some couples view contact with midwives as normal and contact with the doctor to imply presence of an abnormality (11). 
Bearing in mind that the central focus of service delivery including health care is client satisfaction, it is impracticable to continue the neglect to the growing request for male partners to be at delivery. Therefore, it will be necessary to undertake reorientation of birth attendants to accept male partners of parturients as their clients as well, conduct couple education and training as well as provide male-friendly antenatal services (13). Infrastructures in delivery rooms should be reviewed to allow individualized labour and delivery suites which will enable men to accompany their partners during their stay (9). A shift to couple-friendly maternal health services has been identified as a potential enhancer of the quality of care and understanding of information passed across to women (10). A good communication between providers and the male partners will make the men feel-like part of a team and be connected to all that is happening (11) to their advantage and that of their wives and children.

In conclusion, birth attendants in this study are favorably disposed to the presence of male partners at delivery in developing countries. In addition, we are reminded of the feared possibility of litigations if men are allowed at delivery. However, reorientation of birth attendants, upgrading of antenatal infrastructure and content as well as appropriate delivery room modifications are necessary to enable health facilities to meet this need.

We recommend that health care providers be reoriented to accept male partners as their clients while antenatal and delivery suite infrastructure and arrangement should be upgraded to allow the male partners' presence and participation. Health facilities and supervising government ministries should improve the skill of birth attendants and consider a change of protocol to allow men at labour and delivery. In addition, employers of awaiting-fathers should allow them time for antenatal visits, labour and delivery.

\section{REFERENCES}

1. Hodnett ED, Osborn RW. Effects of continuous intrapartum professional support on childbirth outcomes. Research Nursing Health 1989;12: 2907.
2. Adeniran AS, Aboyeji AP, Fawole AA, Balogun OR, Adesina KT, Adeniran IP. Male partners' Role during pregnancy, Labour and Delivery: Expectations of Pregnant Women in Nigeria. Int $J$ Health Sci (Qassim) 2015; 9(3): 313-21.

3. Ainslie TN. Teaching clinical ethics using case study resuscitation. Crit Core Nurse 2005; 25(1): 38-44.

4. Gbinigie NI, Alderson ML, Barclay PM. Informed consent and fainting fathers. Anaesthesia 2001; 56(6): 503-4.

5. Ellison S. Nurses attitude towards family present during resuscitation effect and intensive procedures. J Emerg Nursing 2003; 12: 515-21.

6. Gutman Y, Tabak N. The intention of delivery room staff to encourage the presence of husbands/ partners at caesarean section. Nursing Res Practice 2011. Article ID: 192649 doi:10.1155/2011/192649.

7. Tarkka MJ, Paunonen M, Laippala P. Importance of the midwife in the first time mother's experience of childbirth. Scan J Caring Sci 2000; 14: 184-90.

8. Araoye MO. Research Methodology with Statistics for Health and Social sciences. Ilorin: Nathadex Press; 2003. p.115-121.

9. Kwambai TK, Dellicour S, Desai M, et al. perspectives of men on antenatal and delivery care service utilization in rural western Kenya: a qualitative study. BMC Pregnancy Childbirth 2013; 13: 134 .

10. Mullany BC. Barrier to and attitudes towards promoting husband's involvement in maternal health in Katmandu Nepal. Soc Sci Med 2006; 62(1): 2798-809.

11. Longworth HL, Kingdon CK. Fathers in the birth room: What are they expecting and experiencing? A phenomelogical study. Midwifery 2011; 27(5): 588-94.

12. Karen KL, Paterson-Brown S. How do fathers feel after accompanying their partners in labour and delivery? J Obstet Gynaecol 2002; 22(1): 11-5.

13. Mullick S, Kunene B, Wanjiru M. Involving men in maternity care: health service delivery issues. Agenda 2005:124-135. Available at: http://www.jstor.org/stable/4066710. Accessed on 15th April, 2016.

14. Robinson SM, Mackenzie-Ross S, Hewson GL, Egleston CV, Provost AT. Psychological effects of witnessed resuscitation on bereaved relatives. Lancet 1998; 352: 614-7.

DOI: http://dx.doi.org/10.4314/ejhs.v27i2.2 